\title{
Criterios \\ Restauración del Atlas Mayor o Geografía Blaviana. Nuevas técnicas de Intervención
}

Luciano Pardo Pardo

Universidad de Valencia

\section{Resumen}

El proceso de restauración seguido en el Atlas Mayor o Geografia Blaviana muestra la búsqueda de nuevos procedimientos técnicos de intervención, en respuesta a las dificultades que planteaba el grado de deterioro y la complejidad tecnológica de la obra. El resultado ha sido un nuevo sistema al que denomino reintegración mecánica en seco; es la solución indicada para la restauración de documentos que por su nivel de deterioro y características materiales, tanto del soporte como de los elementos sustentados, es necesario reintegrar mecánicamente pero arriesgado someterlos a tratamientos húmedos, como los realizados en la reintegradora tipo vinyector.

\section{Palabras clave}

\section{Intervención}

Patrimonio documental

Conservación

Atlas

Atlas Mayor o Geografía Blaviana

Biblioteca Universitaria de Valencia

Blaeu, Juan

S. XVII

Libros

Reintegración mecánica

\section{Introducción histórica}

El descubrimiento y la exploración de nuevos territorios en todo el mundo y el establecimiento de nuevas rutas comerciales a lo largo de los siglos XVI y XVII hicieron necesaria una continua modificación de los mapas para incluir los datos más recientes aportados por marineros y exploradores. El Atlas Mayor o Geografía Blaviana condensa la evolución experimentada por la geografía durante estos siglos y constituye la culminación de una época destacada de la cartografía de los Países Bajos.

La publicación a principios del s. XV en Florencia de la Geographia de Ptolomeo refuerza notablemente el concepto científico de la geografía, que llega a ser considerada como una rama de las matemáticas. La necesidad de una localización exacta de estas rutas y territorios motivó la investigación de diversos métodos de proyección y cálculos para la representación cartográfica. Gerardus Mercator (1512-1594) y Abraham Ortelius (1527-1598) fueron dos de los primeros cartógrafos que revisaron los métodos de Ptolomeo; la proyección cilíndrica que concibió Mercator para sus mapas fue de gran valor para los navegantes.

El desarrollo de la imprenta favoreció al mismo tiempo la creación de numerosas editoriales en los Países Bajos y la difusión del material impreso hacia el resto de Europa.

Willem Janszonn Blaeu (1571-1638) fue un reputado astrónomo dedicado a la edición tanto de globos celestes y terrestres, como de atlas, cartas náuticas, etc. En 1629 amplió sus fondos de mapas con la compra de las planchas del atlas de Ortelius, siendo sus publicaciones más importantes el Atlantis appendix (1630), Appendix theatri A. Ortelii et atlantis G. Mercatoris (1631) y sobretodo el Novus atlas o Theatrum orbis Terrarum en dos volúmenes (1634-1635).

Juan Blaeu (1596-1673) se hizo cargo en 1636, junto con su hermano Cornelis (?-1644), de la imprenta de su padre Willem Blaeu, realizando un importante número de ediciones entre las que cabe destacar la continuación del Novus atlas iniciado por su padre, con la publicación del volumen de Italia en 1640, Inglaterra y Gales en 1645, Escocia e Irlanda en 1654 y China en 1655, que fueron un claro precedente de su obra más importante: el Atlas Mayor (1658-1672), compuesto por un número de volúmenes variable, entre nueve y doce según la edición y publicado en varios idiomas, holandés, latín, francés, alemán y castellano.

La Biblioteca Histórica de la Universidad de Valencia conserva la edición española formada por diez volúmenes. Los de África y América no pudieron acabarse a causa de un incendio producido en el taller de Juan Blaeu en 1672. 


\section{$090-091$ \\ Criterios}

Restauración del Atlas

Mayor o Geografía

Blaviana. Nuevas técnicas

de Intervención

\section{PH43 - Abril 2003}

\section{Descripción general de la colección}

Volúmenes conservados en la Biblioteca Histórica de la Universidad de Valencia

I (Y-29/2) Atlas Universal y Cosmográfico de los orbes celestes y terrestre (Europa Nórdica).

II (Y-29/3) Nuevo Atlas de las partes orientales de Europa.

III (Y-29/4) Parte del Atlas Mayor o Geographia Blaviana, que contiene las cartas y descripciones de Alemania.

IV (Y-29/5) Países Baxos o la Belgia Real. (sic)

V (Y-29/6) Nuevo Atlas del Reyno de Inglaterra. (sic)

VI (Y-29/7) Nuevo Atlas de los Reynos de Escocia e Yrlanda. (sic) VII (Y-29/8) Atlas Mayor o Geographia Blaviana, que contiene las cartas y descripciones de Francia y Helvetia.

VIII (Y-29/9) Parte del Atlas Mayor o Geographia Blaviana, que contiene las cartas y descripciones de Italia.

IX (Y-29/10) Atlas Nuevo de la Extrema Asia, o descripción geographica del Imperio de los Chinas. (sic)

X (Y-29/11) Atlas Mayor o Geographia Blaviana, que contiene las cartas y descripciones de España.

\section{Encuadernación}

Rígida en pergamino, encolada por entero, con dorados, cintas rojas y azules para el cierre en el corte delantero, alternándose la de color azul arriba y la roja abajo en la tapa anterior y a la inversa en la posterior, (excepto en 3 volúmenes, el de Europa Nórdica, Alemania y Paises Bajos, donde los colores están intercambiados).

Lomo: hueco, plano, y sin relieve de nervios.

Pastas: de cartón de $4 \mathrm{~mm}$., ángulos cuadrados, cantos rectos. Guardas: dos hojas con solapa.

Costura: sobre 7 nervios simples de piel de $13 \mathrm{~mm}$. de anchura, más cadeneta; punto salteado, hilo de lino.

Cabezadas: núcleo redondo de piel, insertada a la pasta. Hilo de color verde, punto sencillo (excepto en 4 volúmenes donde se alternan los colores rojo y azul, Europa Oriental, Inglaterra, Paises Bajos y Escocia e Irlanda).

Cortes: guillotinados dorados.

El volumen de Inglaterra presenta las siguientes diferencias en la encuadernación:

$>$ No tiene decoración de dorados en las tapas.

$>$ La costura es sobre 6 nervios redondos y simples, desdoblados para insertarse a la tapa, más cadeneta, punto salteado, hilo de lino.

\section{Cuerpo del libro}

Datos correspondientes a los 7 volúmenes intervenidos.

Formato: folio marca mayor. El volumen de menor tamaño es el de Italia con 523 x 346 mm. y el de mayor el de Escocia con 540 x $356 \mathrm{~mm}$.

Composición: 822 duernos y 216 folios montados sobre cartivanas con un total de 3.720 páginas distribuidas por volúmenes de la siguiente manera:

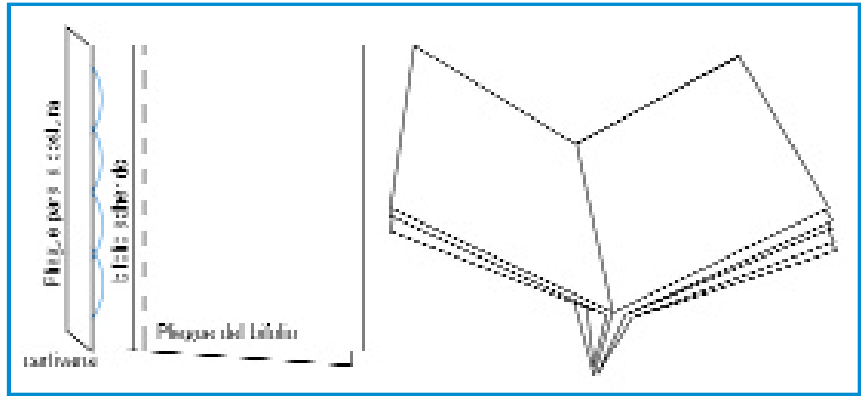

Alemania: 142 duernos y 37 folios, 642 páginas. Países Bajos y Bélgica: 130 duernos y 34 folios, 588 páginas. Inglaterra: 120 duernos y 29 folios, 538 páginas.

Escocia e Irlanda: 103 duernos y 15 folios, 442 páginas. Francia: 145 duernos y 25 folios, 630 páginas.

Italia: 100 duernos y 29 folios, 458 páginas.

España: 82 duernos y 47 folios, 422 páginas.

Escritura: romana, varios tamaños, texto a dos columnas, apostillas y reclamos.

Ilustraciones: frontispicio en todos los volúmenes menos en el de Alemania e Italia. 423 mapas a doble página y 13 en página sencilla, todos grabados calcográficos coloreados a mano, menos 97 de Alemania y uno de Inglaterra que son en blanco y negro. Capitales e ilustraciones xilografiadas.

\section{Descripción del grado de deterioro}

La obra presenta una gran variedad de daños originados por múltiples causas que afectan irregularmente a los distintos volúmenes.

La tipología y envergadura del deterioro queda resumida en el cuadro de la página siguiente.

Cabe destacar la abundancia de materiales sólidos adheridos sobre la superficie del papel en los volúmenes de los Países Bajos, Inglaterra y Escocia, en los que también se aprecian multitud de aureolas de humedad y manchas causadas por microorganismos, origen de una extrema fragilidad en amplias zonas del papel.

Desde el punto de vista de la restauración, el deterioro podríamos agruparlo en dos categorías: deterioro con carácter progresivo y deterioro con carácter estable.

\section{Deterioro con carácter progresivo}

Es el más grave de todos, no sólo por su extensión sino por que su actividad continúa y aumenta con el paso del tiempo. Dentro de este apartado se encuentran los ocasionados por la acidez, microorganismos, así como todos los materiales sólidos y líquidos absorbidos por el papel. Han sido la causa de importantes variaciones de color tanto en el soporte como en las tintas y han provocado la degradación del papel en amplias zonas de algunos volúmenes, llegando incluso a la pérdida de soporte y la de los elementos sustentados que contiene.

\section{Deterioro con carácter estable}

Se caracteriza por ser un daño exclusivamente físico-mecánico que no aumenta con el paso del tiempo a no ser por una manipulación inadecuada de los libros. Dentro de este apartado se encuentran los daños ocasionados en su momento por anóbidos (galerias) y por el uso (desgarros, roces y lagunas), que han provocado igualmente pérdidas de soporte en algunos volúmenes, tanto en el cuerpo de los libros como en las encuadernaciones. 


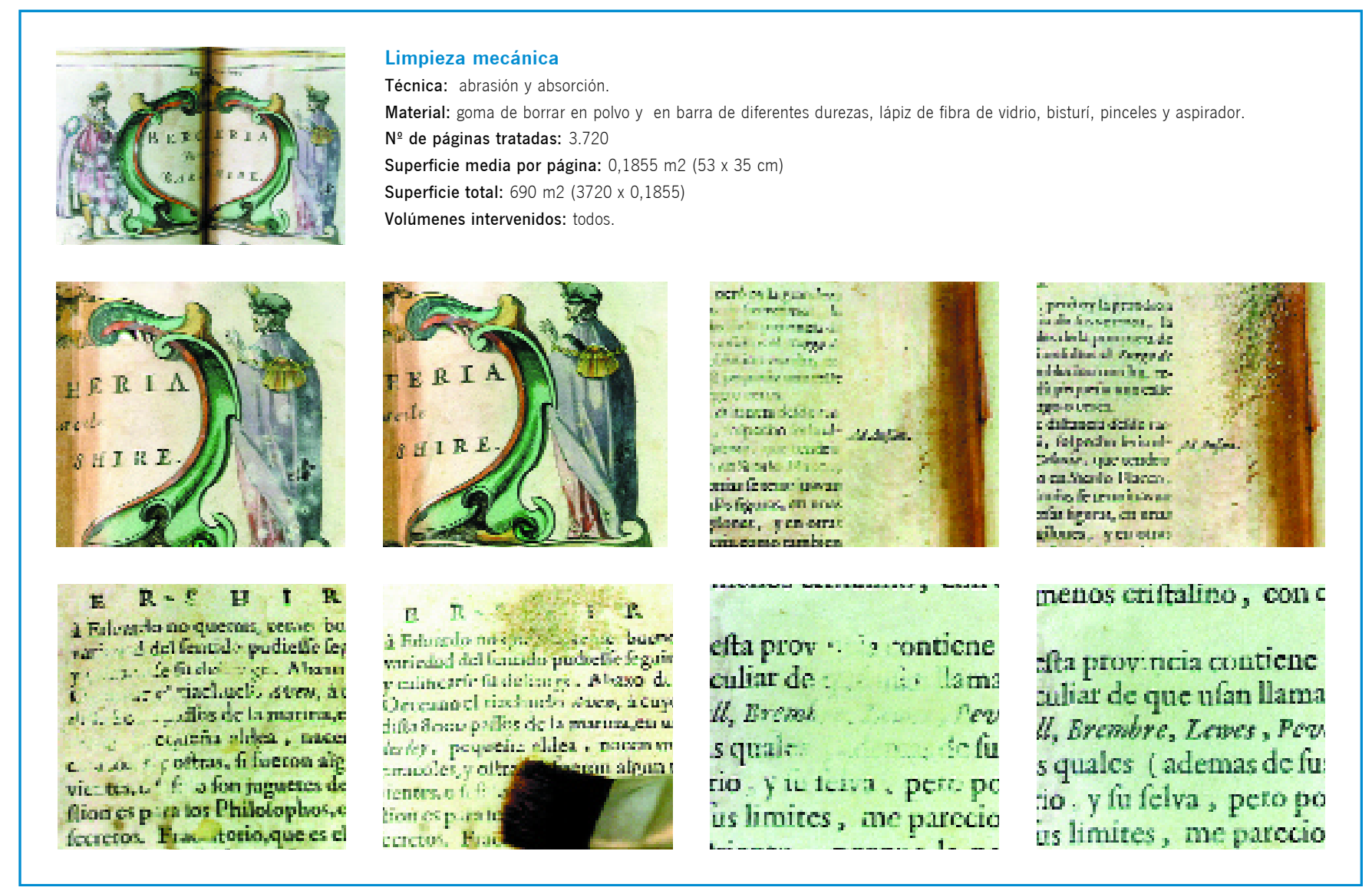

\begin{tabular}{|c|c|c|c|c|c|c|}
\hline Volumen & $\begin{array}{l}\text { Galerias } \\
\text { insectos }\end{array}$ & $\begin{array}{l}\text { Aureolas de humedad, } \\
\text { microorganismos. }\end{array}$ & $\begin{array}{l}\text { Acidez, hojas } \\
\text { oscurecidas }\end{array}$ & $\begin{array}{l}\text { Acidez } \\
\text { cartivanas }\end{array}$ & $\begin{array}{l}\text { Desgarros } \\
\text { Parches }\end{array}$ & Encuadernación \\
\hline Alemania & Pocas & & Algunas & Algunas & Algunos & Lomo desgarrado nervios rotos \\
\hline Países Bajos & & Abundantes & & Todas las hojas & Multitud & Pequeña laguna \\
\hline Inglaterra & Abundantes & Abundantes todas las hojas & Múltiples & Todas las hojas & Multitud & No original \\
\hline Escocia e Irlanda & & Numerosas & Múltiples & Todas las hojas & Multitud & Pequeña laguna \\
\hline Francia & & & Múltiples & & Primeras hojas & Nervios rotos, tapas sueltas \\
\hline Italia & & & Múltiples & & & \\
\hline España & & & Múltiples & & Primeras hojas & Nervios rotos, tapas sueltas y laguna \\
\hline
\end{tabular}

\section{Criterios de restauración}

En base a la tipología, extensión y gravedad del deterioro sufrido por la colección, se propone una intervención dirigida fundamentalmente a la neutralización de todos los factores causantes de la degradación y reflejados en el punto "deterioro con carácter progresivo", así como a la consolidación de zonas débiles y a la reintegración y refuerzo de lagunas y desgarros que impliquen un riesgo para la integridad de la obra.

El grave deterioro del volumen de Inglaterra hacía absolutamente necesaria la utilización de técnicas de restauración que actuasen profundamente sobre el soporte y las tintas, asegurando una neutralización total de los agentes causantes del deterioro. Para lograr este objetivo será necesario desencuadernar el volumen, actuación que por otra parte no ha representado ninguna pérdida de información histórica o tecnológica, ya que ni la encuadernación ni la costura son originales y no contienen ningún elemento decorativo. El desmontaje del libro ha permitido además descubrir que se reutilizaron las pastas originales recortadas (llevan la impronta de los hierros del dorado); también se encontraron las huellas de la costura original que han servido de guía para la realización de la nueva costura.

\section{Informe microbiológico}

Las muestras que se tomaron sobre 11 puntos del volumen de Inglaterra, distribuidos por las zonas con mayor evidencia de actividad microbiana, dieron un resultado negativo en todos los cultivos. Del informe remitido por José Pedro Martínez García, catedrático de microbiología y Daniel Gozalbo Flor, profesor titular de microbiología, ambos del Departamento de Microbiología y Ecología de la Universidad de Valencia, extraemos el siguiente texto: "Como conclusión final, se puede afirmar que el estado actual del libro examinado desde el punto de vista microbiológico es aceptable, no siendo necesario ningún tratamiento antimicrobiano (antibacteriano y antimicótico) durante el proceso de restauración, para su conservación futura, dado que la microbiota que en su momento pudo ser responsable, al menos en parte, de la degradación y los daños apreciados, no es actualmente viable".

\section{Restauración}

La selección de la técnica adecuada para cada uno de los tratamientos en el proceso de restauración ha venido condicionada según se tuviese que operar sobre tomos encuadernados, hojas 


\section{$092-093$}

\section{Criterios}

Restauración del Atlas

Mayor o Geografía

Blaviana. Nuevas técnicas

de Intervención

\section{PH43 - Abril 2003}

sueltas (volumen de Inglaterra) o mapas (tintas solubles). Esta es la razón por la que en algunos tratamientos, como la desacidificación, se han empleado hasta tres técnicas diferentes de aplicación (véase esquema de la intervención).

\section{Cuerpo del libro}

Una vez concluida la fase de recopilación de información y realizadas las pruebas necesarias para asegurar una correcta intervención, se comenzó por el desmontaje del volumen de Inglaterra para un proceso de restauración diferenciado del resto de volúmenes. Del mismo modo se procedió con algunas hojas del volumen de los Países Bajos y los frontispicios de España y Francia por el grave deterioro que sufrían.

A continuación iniciamos la limpieza mecánica utilizando técnicas de abrasión y absorción, mediante gomas de borrar en polvo y en barra de diferentes durezas, lápiz de fibra de vidrio, bisturí, pinceles y aspirador. Su ejecución fue especialmente laboriosa por la enorme superficie a tratar, unas 3720 páginas $\left(690 \mathrm{~m}^{2}\right)$, así como por la gran cantidad de polución y materiales sólidos adheridos; su eliminación fue indispensable para evitar la penetración en el soporte durante tratamientos posteriores. Una dificultad añadida la ofrecian multitud de zonas débiles que desaconsejaban el empleo de métodos abrasivos e incluso la absorción, en este caso se utilizó una aspiración suave, colocando un filtro entre el documento y la boca de aspiración para proteger la zona.

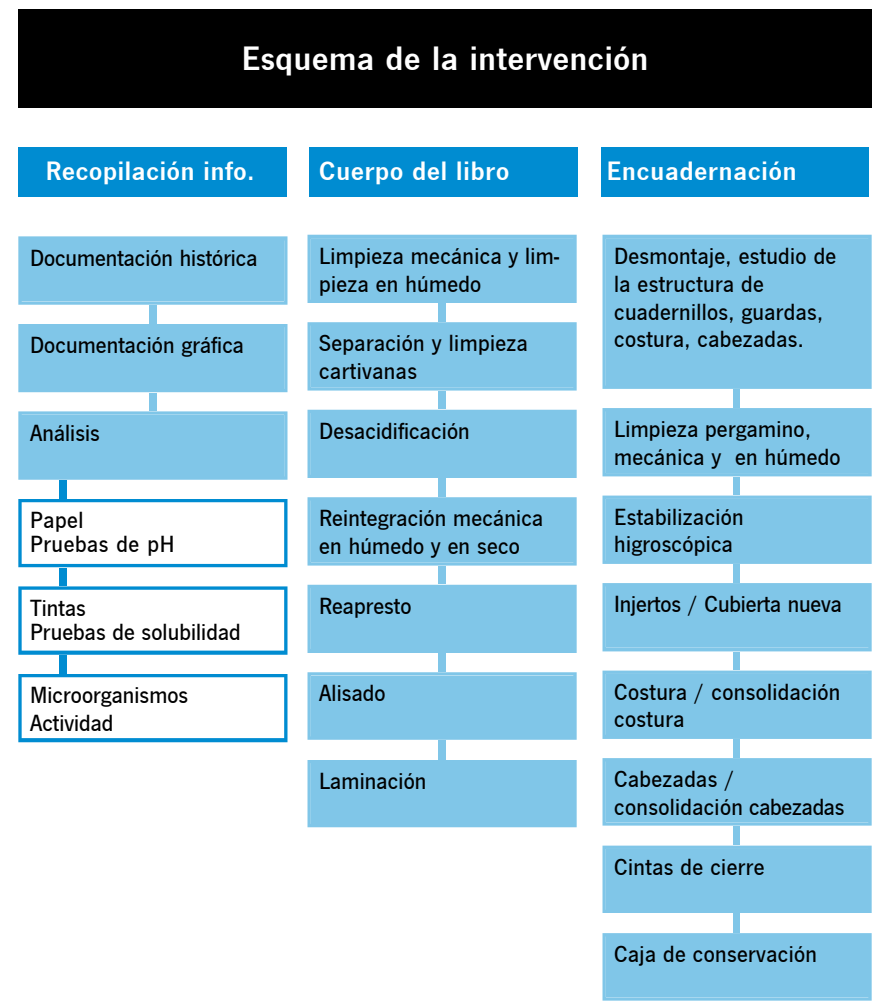

\section{Esquema de la intervención}

Limpieza en húmedo

Técnica: baño.

Material: agua fría.

№ de páginas tratadas: 324

Volúmenes intervenidos: Inglaterra.

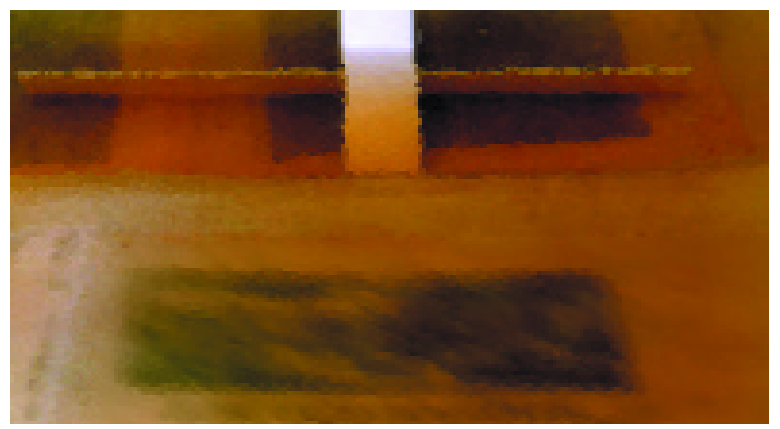

Desacidificación

Técnica: baño.

Material: hidróxido cálcico.

№ de páginas tratadas: 324

Volúmenes intervenidos: Inglaterra.

Técnica: pulverización

Material: hidróxido cálcico y etanol al 50\%.

№ de páginas tratadas: 464

Volúmenes intervenidos: Alemania, Paises Bajos, Francia, Italia y España.

Técnica: pulverización

Material: óxido de magnesio.

№ de páginas tratadas: 217 mapas, total de páginas: 858

Volúmenes intervenidos: todos menos Alemania.

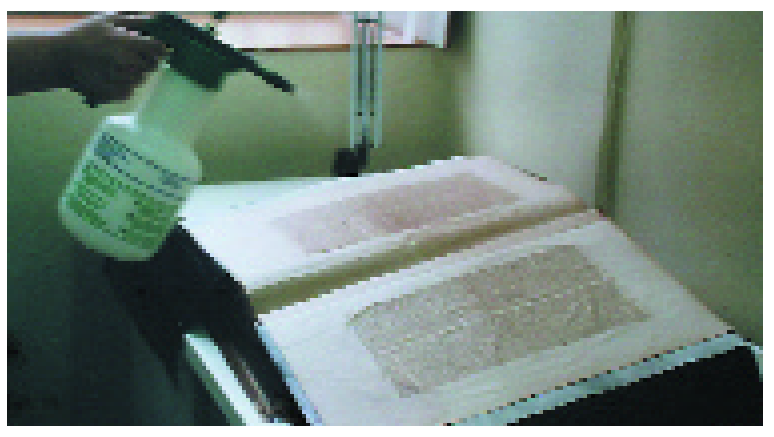

Tratamiento de hojas impresas con hidróxido cálcico pulverizado.
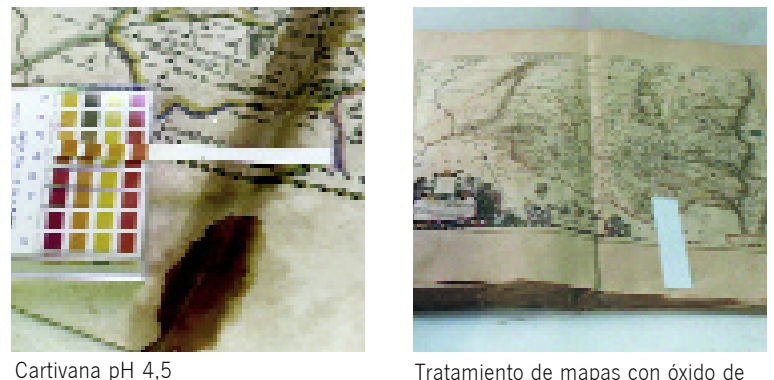

Tratamiento de mapas con óxido de magnesio pulverizado.

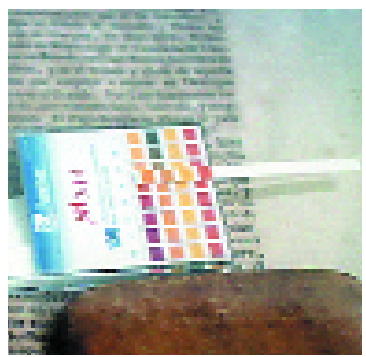

Hoja antes del tratamiento: $\mathrm{pH} 4,5$ (ácido)

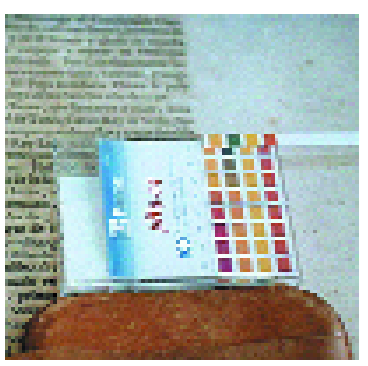

Hoja después del tratamiento. $\mathrm{pH} 7$. 

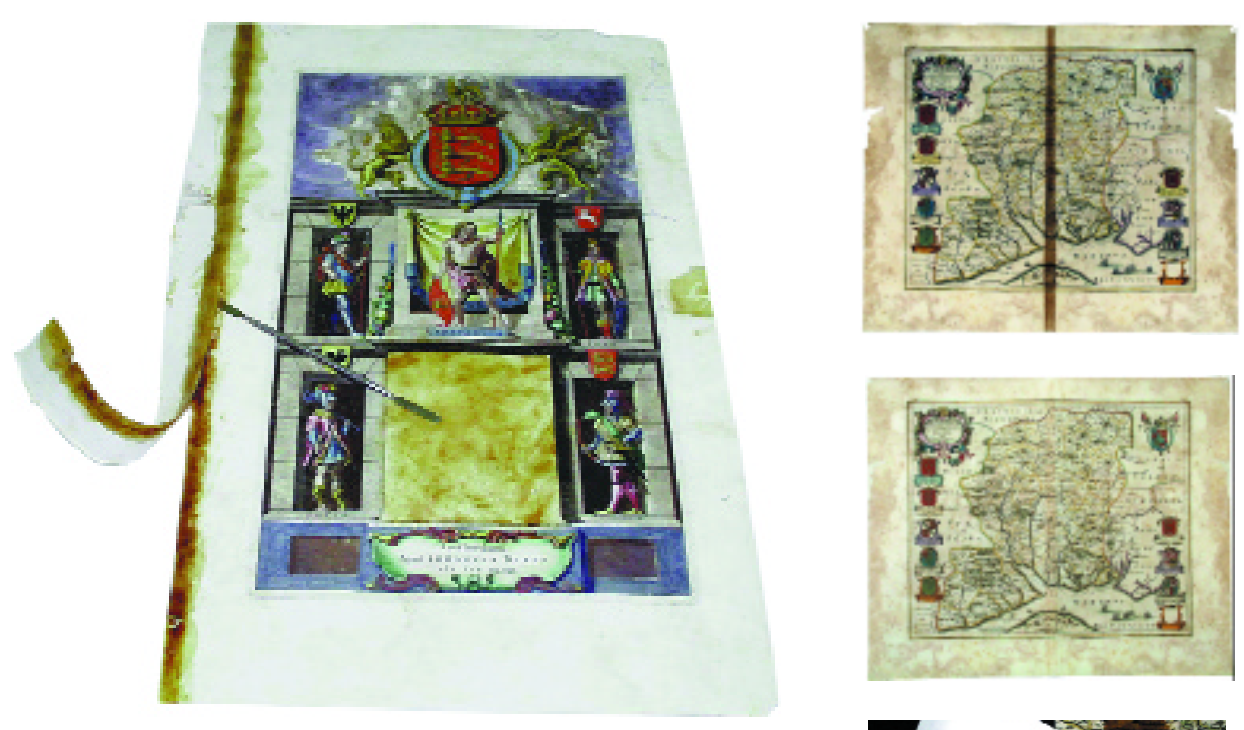

La eliminación de cola de gelatina en las cartivanas de los mapas ha sido una intervención necesaria por dos razones:

$1^{\text {a }}$ la acidez de la cola $(\mathrm{pH} 4,5)$ ha provocado una notable degradación que continúa progresando en el papel.

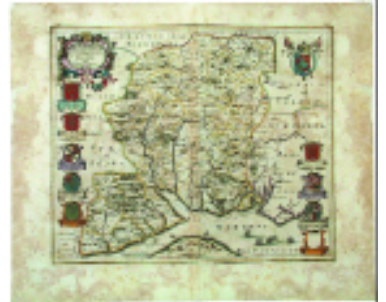

$2^{\text {a }}$ la mancha impide una libre visualización de la imagen.

Las pruebas de solubilidad de algunos colores indican una sensibilidad al contacto con la humedad, por lo que se evitan todos los métodos por baño y se utilizan técnicas de tratamiento local, previa protección de las zonas afectadas.

Cartivanas

Técnica: tratamiento local.

Material: metilcelulosa, enzimas.

№ de páginas tratadas: 57 mapas.

Volúmenes intervenidos: Inglaterra.

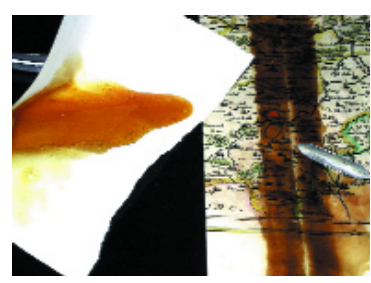

La limpieza en húmedo se realizó sobre las hojas impresas del volumen de Inglaterra (324 páginas en total). El manejo de las inmensas hojas tuvo que realizarse por dos personas con especial cuidado para evitar cualquier daño.

Una de las intervenciones realizadas sobre 57 mapas del volumen de Inglaterra fue la separación de cartivanas; el objetivo consistía en eliminar la cola de gelatina y en la medida de lo posible la mancha producida por esta; las razones que han motivado esta operación han sido dos:

1. la acidez de la cola $(\mathrm{pH} 4,5)$ había provocado una notable degradación que continuaba progresando en el papel.

2. la mancha ennegrecida de la cola dificultaba la visualización de la imagen.

Las pruebas de solubilidad de algunos colores indicaban una sensibilidad al contacto con la humedad, por lo que se evitan todos los métodos por baño y se utilizan técnicas de tratamiento local, previa protección de las zonas afectadas. El rastro de la mancha que aún permanecía después del tratamiento se redujo con peróxido de hidrógeno a 7 volúmenes, neutralizado con amoniaco.

Para la desacidificación se utilizan tres métodos diferentes de aplicación según las características y condiciones de los materiales a tratar. El primero se realizó por inmersión de las hojas impresas del volumen de Inglaterra (324 páginas) en una solución saturada de hidróxido cálcico. Para todas las hojas impresas con indicios de acidez en volúmenes sin desencuadernar, se efectuó una aplicación por pulverización de una mezcla de hidróxido cálcico en solución saturada con etanol al 50\%, para favorecer la evaporación; se trataron un total de 464 páginas de los volúmenes de Alemania, Países Bajos, Francia, Italia y España. En la desacidificación de mapas coloreados con sintomas de acidez y debido a la solubilidad de algunas tintas en medios acuosos, se opta por la pulverización de un compuesto comercial a base de óxido de magnesio por su reconocida efectividad e inocuidad con las tintas; se trataron 217 mapas de 6 volúmenes ya que el de Alemania tiene los mapas sin colorear. Posteriormente se efectúan pruebas para comprobar la eficacia del tratamiento en cada caso.

La ingente cantidad de hojas que habian perdido total o parcialmente su consistencia hizo necesario un reapresto, mediante la aplicación por impregnación de un adhesivo a base de hidroxipropilcelulosa; la característica que interesaba de este producto era su capacidad para ser disuelto en etanol, solvente que cumplía con dos condiciones, no afectaba a los colores de los mapas al tiempo que aceleraba el secado en los volúmenes encuadernados. Los volúmenes intervenidos fueron Países bajos y Escocia, y los mapas del tomo de Inglaterra, 836 páginas en total.

La reintegración mecánica ofrecia en su inicio problemas aparentemente insalvables, el tamaño de las hojas, el número de lagunas, y sobretodo la solubilidad de las tintas de los mapas. Dado el interés que ofrece el tema, por el avance que supone para ésta técnica, se tratará separadamente en el punto "Innovaciones técnicas".

La reparación de desgarros se realizó manualmente, con papel japonés de diferentes gramajes y una mezcla de metilcelulosa y PVA, sobre un total de 858 páginas de los volúmenes de Escocia, Italia y España.

Finalmente las hojas que por su extremada fragilidad no alcanzaron el grado necesario de solidez después del apresto, se someten a una nueva intervención de refuerzo; la técnica utilizada ha sido la laminación en prensa de vacío y calor, con papel japonés de 6 gr. y adhesivo paraloid en película como soporte material. El número de páginas tratadas fueron 176 de los volúmenes de Países Bajos, Inglaterra, Francia y España.

\section{Encuadernaciones}

Fue necesario separar la encuadernación del cuerpo del libro en cuatro volúmenes, el de España y Alemania debido a los grandes desgarros del lomo, el de Francia por la rotura casi total de los nervios, mientras que en el caso de Inglaterra fue la propia intervención la que obligó a la separación. 


\section{$094-095$}

\section{Criterios}

Restauración del Atlas

Mayor o Geografía

Blaviana. Nuevas técnicas

de Intervención

\section{PH43 - Abril 2003}

El proceso de restauración de las encuadernaciones se inició en todos los volúmenes con la limpieza mecánica, con técnicas similares a las empleadas en el cuerpo del libro, seguida de una limpieza mediante aplicación local de torundas de algodón humedecidas en agua y etanol. Posteriormente se realizaron injertos y refuerzos en el lomo con pergamino de cabra y PVA, en los volúmenes de Alemania, Países Bajos, Escocia y España; al volumen de Inglaterra se le hizo una cubierta nueva.

La costura en el volumen de Inglaterra se realiza sobre 7 nervios planos de piel más cadeneta, punto salteado, reproduciendo la original según las huellas encontradas al desmontar el libro, utilizando hilo de lino para la costura y piel de cabra al alumbre para los nervios. Las costuras de los volúmenes a los que separamos la cubierta, Alemania, Francia y España, se reforzaron colocando tiras de piel de cabra al alumbre cosidas sobre los nervios rotos, que sirvieron de soporte a su vez para coser los cuadernillos sueltos del principio y final de los volúmenes.

Las cabezadas del volumen de Inglaterra se realizan sobre núcleo redondo de piel, punto sencillo, alternando hilo de seda de color rojo y azul; en los volúmenes de Alemania y España se realizan de igual manera pero con hilo de color verde, y en el de Francia sólo se hace la inferior. Las cabezadas superiores desprendidas de los volúmenes de Francia e Italia se consolidan con hilo de seda del mismo color.

Por ser el volumen de Inglaterra, por ser el único al que se le realiza una nueva encuadernación, se le colocan cintas de cierre rojas y azules, de poliéster y seda respectivamente, para completarla.

Para finalizar se les aplica un masaje de polietilenglicol a todos los volúmenes para la estabilización higroscópica del pergamino.

\section{Innovaciones técnicas}

\section{Reintegración en seco del soporte}

Las primeras reflexiones sobre la técnica conveniente para la reintegración de los mapas del volumen de Inglaterra me llevaban inevitablemente al terreno de la pura elucubración. Las alternativas técnicas disponibles en la actualidad para la reintegración del soporte de documentos -reposición de papel en las zonas desaparecidas o lagunas- se reducen básicamente a dos: una manual y otra mecánica mediante reintegradora tipo vinyector.

La manual, más antigua y eficaz, es también la más costosa debido a la necesidad de adaptar un papel ya formado, de características similares al original, sobre las zonas deterioradas del documento mediante diferentes métodos de recorte. En el caso que nos ocupa, tanto el gran tamaño de las hojas de los atlas como el considerable número de lagunas, desaconsejaban la

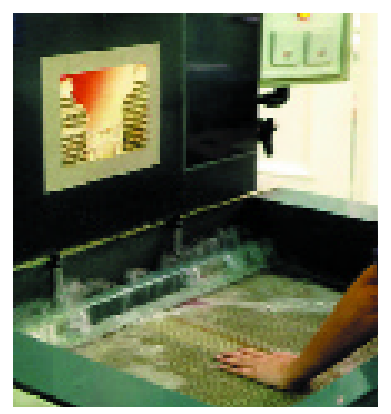

Reintegración mecánica

Técnica: reintegración en húmedo. Material: mezcla de fibras de conifera, lino y algodón.

№ de páginas tratadas: 336 Volúmenes intervenidos: Inglaterra y Paises Bajos.
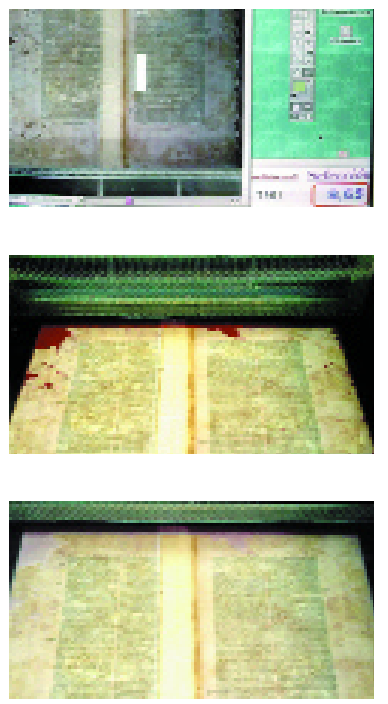

\section{Reapresto}

Técnica: impregnación y baño. Material: metilcelulosa.

№ de páginas tratadas: 324 Volúmenes intervenidos: Inglaterra.

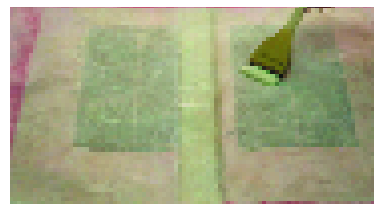

Técnica: impregnación

Material: Hidroxipropilcelulosa.

№ de páginas tratadas: 836

Volúmenes intervenidos: Escocia,

Paises Bajos e Inglaterra.

reintegración manual por el excesivo tiempo que hubiese sido necesario para su realización.

La reintegración mecánica sin embargo es mucho más resolutiva, pero con una serie de limitaciones a considerar. El riesgo de solubilidad de los colores en los mapas hacía impensable una reintegración mecánica a la manera tradicional, ya que este procedimiento conlleva la inmersión de los documentos en agua.

La necesidad de un nuevo procedimiento que evitase el inconveniente de la humedad en la reintegración mecánica fue la idea inicial sobre la que fui desarrollando un sistema al que llamo reintegración mecánica en seco; en él se ofrece una nueva alternativa que permite operar sobre cualquier tipo de documento que no pueda ser tratado por medios acuosos, obteniendo además un alto nivel de calidad en los injertos así como una notable ra- 


\section{Reintegración mecánica}

Técnica: reintegración en seco.

Material: mezcla de fibras de conifera, lino y algodón fijadas con hidroxipropilcelulosa.

№ de páginas tratadas: 57 mapas, total de páginas: 214 .

Volúmenes intervenidos: Inglaterra, Francia y España.
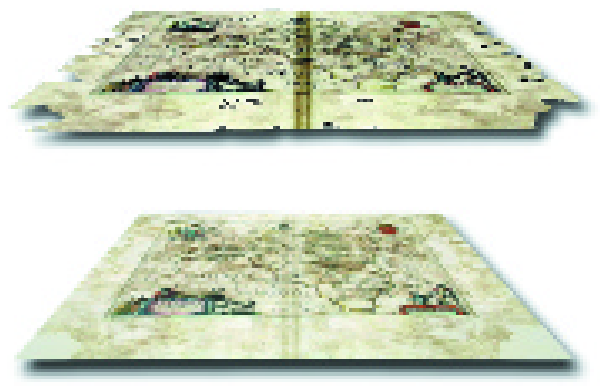

El riesgo de solubilidad de los colores en los mapas hacia impensable una reintegración mecánica a la manera tradicional, ya que este procedimiento conlleva la inmersión de los documentos en agua.

Por otro lado, el tamaño y el considerable número de lagunas existentes no permitían una reintegración manual por el excesivo tiempo que hubiese sido necesario para su realización.

Para resolver este problema he desarrollado un nuevo sistema al que llamo reintegración mecánica en seco, que permite operar sobre cualquier tipo de documento que no pueda ser tratado por medios acuosos, obteniendo un alto nivel de calidad en los injertos y una gran rapidez en la ejecución.

Con este original sistema evitamos la utilización del agua como vehículo de transporte de fibras de celulosa hacia las lagunas del papel, eludiendo todo contacto de las tintas solubles con la humedad.

Las fibras se fijan con un adhesivo aplicado a brocha, tipo hidroxipropilcelulosa, cuyo disolvente no afecta a las tintas. A continuación se somete a un prensado suave para nivelar y alisar la pulpa. El prensado con ausencia de humedad minimiza sustancialmente las posibles deformaciones o alteraciones en la textura de los documentos.

pidez en la ejecución; la pura elucubración se convirtió en pura realidad. En este sistema hay un cambio sustancial con respecto a la técnica de reintegración mecánica tradicional, la sustitución del agua por el aire como vehículo de transporte de fibras de celulosa hacia las lagunas del papel, evitando de esta manera cualquier contacto de las tintas solubles con la humedad.

El sistema cuenta básicamente con tres dispositivos, el primero se encarga de la mezcla y acondicionamiento de las fibras, el segundo gestiona la circulación de las fibras dirigiéndolas a través de una campana hacia el tercer dispositivo, la zona de succión. Una vez se han recubierto de fibras las lagunas del soporte, se fijan con un adhesivo tipo hidroxipropilcelulosa, cuyo disolvente no afecta a las tintas.

A continuación se somete a un prensado suave para nivelar y alisar la pulpa. El prensado con ausencia de humedad minimiza

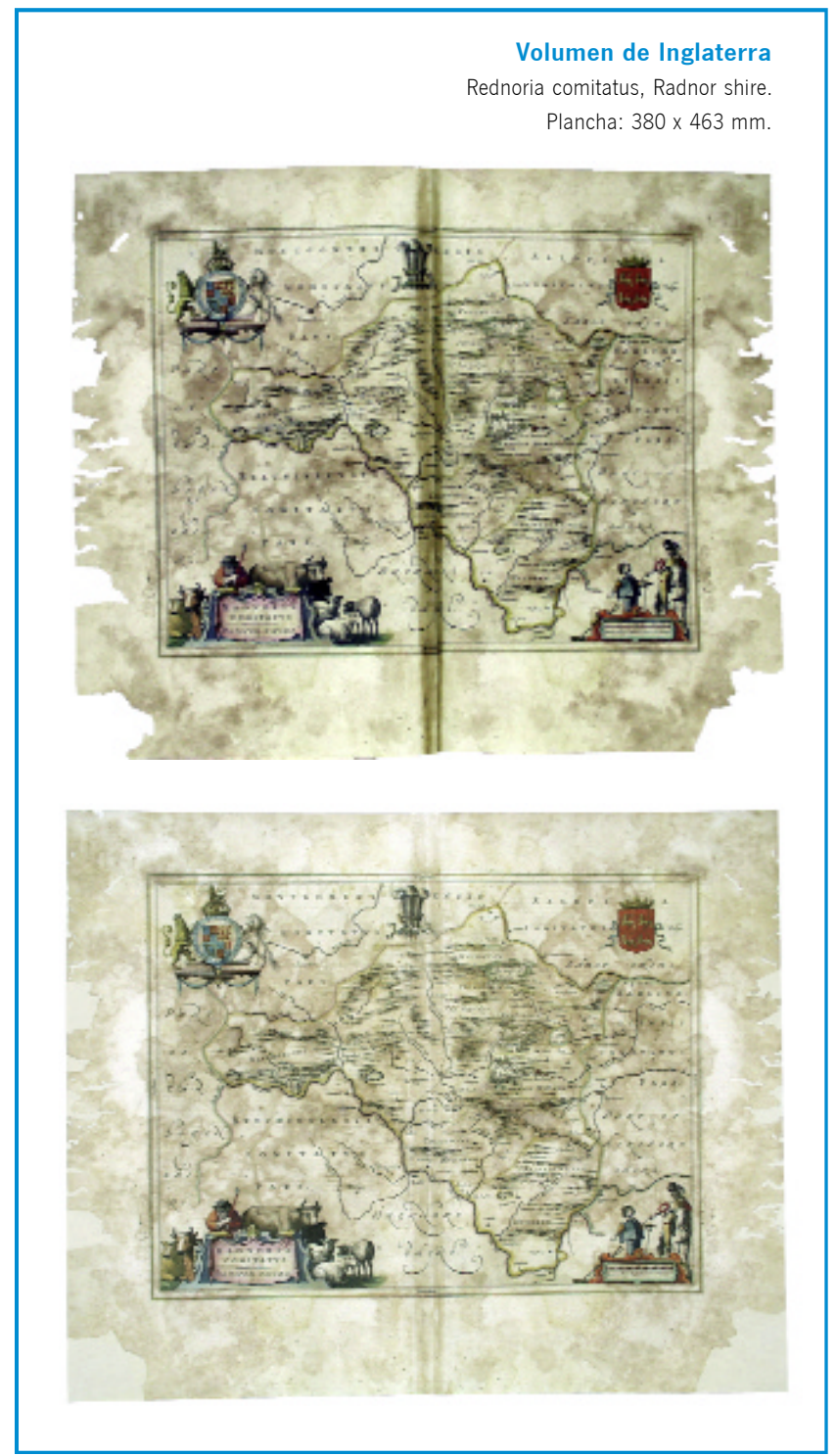

sustancialmente las posibles deformaciones o alteraciones en la textura de los documentos.

Las páginas intervenidas son un total de 214 (57 mapas), correspondientes a los tomos de Inglaterra, Francia y España; el material utilizado es una mezcla de fibras de conifera, lino y algodón adecuada a las características del papel original.

Esta nueva perspectiva me ha permitido experimentar con otros soportes que hasta ahora hubiese sido imposible reintegrar mecánicamente de la misma manera que un documento en papel. Las hojas en pergamino y vitela de códices y documentos manuscritos pueden ser materiales especialmente indicados para la reintegración en seco con fibras de celulosa, dado que con este sistema la deformación de los materiales proteínicos es minima. 


\section{$096-097$ \\ Criterios \\ Restauración del Atlas \\ Mayor o Geografía \\ Blaviana. Nuevas técnicas \\ de Intervención \\ PH43 - Abril 2003}

Dosificador de pulpa de papel para la reintegración mecánica de soporte dañados

El dosificador de pulpa es un sistema que he desarrollado y perfeccionado desde 1994 y que ha demostrado su gran utilidad en la complicada reintegración de las hojas impresas de los atlas (los pliegos median alrededor de $50 \times 68 \mathrm{~cm}$.).

La reintegración mecánica de documentos en papel presenta dos importantes problemas relacionados con la dosificación de pulpa:

a) la valoración objetiva de la cantidad necesaria para la reintegración de una determinada superficie.

b) la medición precisa de esa cantidad de pulpa en suspensión acuosa.

Para solucionar ambos problemas he configurado:

1. Un sistema informático que calcula en un tiempo mínimo la información necesaria relativa al documento a reintegrar:

$>$ gramaje y densidad media del papel original.

> superficie y volumen de la zona a reintegrar, y su peso en gr.

> volumen en $\mathrm{ml}$. de suspensión necesaria y código para programar la medición del dosificador.

Una cámara fotográfica digital situada sobre la reintegradora permite captar, en pocos segundos, la imagen del documento instalado en la máquina. A continuación un programa de ordenador realiza sobre ésta imagen el cálculo de la cantidad de pulpa necesaria para la reintegración de sus lagunas.

2. Un dosificador que realiza la medición, y que además acondiciona la suspensión para que se encuentre perfectamente homogeneizada cuando sea depositada en la reintegradora. La adición se realiza al mismo tiempo que se llena de agua el seno superior, por lo que el reparto de la pulpa sobre el documento resulta óptimo.

Se han reintegrado 336 páginas de los volúmenes de Inglaterra y Paises Bajos, con una mezcla de fibras de lino, conifera y algodón, con densidad aproximada a las características del papel original.

A las fibras utilizadas se añadió un porcentaje de fibras de conífera sin blanquear para minimizar el contraste con el color del papel original, no obstante la desigualdad del tono en las hojas hacía difícil la aproximación en algunos casos.

\section{Conclusiones}

La restauración del Atlas Mayor o Geografía Blaviana ha constituido, dada la diversidad y complejidad tecnológica de la obra, un estímulo decisivo para la búsqueda de nuevos procedimientos que facilitasen o permitiesen la intervención más adecuada a cada dificultad planteada.
Encuadernación

Volumen: Inglaterra

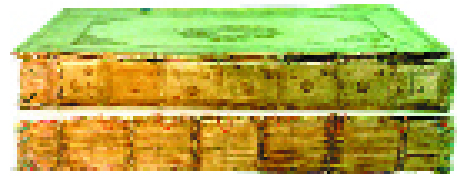

Análisis costura: situación de nervios antiguos en el volumen de Inglaterra (bajo). Comparación con el volumen de España (arriba).

Las huellas de una costura anterior (hilo rojo) coinciden, en el número de nervios y en la distancia entre ellos, con la costura original del otro volumen.

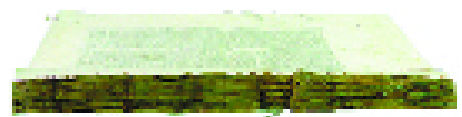

Descosido y eliminación de refuerzos del lomo.

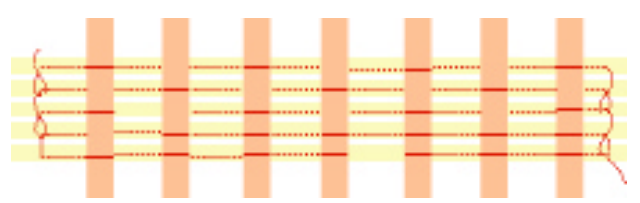

Estructura original de la costura
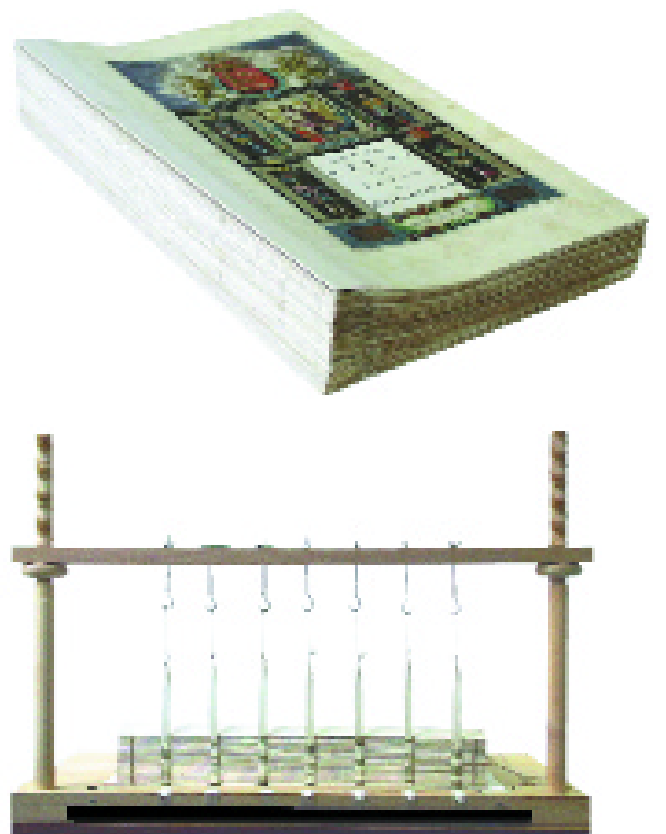

La costura se realiza con la misma estructura que la original: 7 nervios planos de piel más cadeneta, punto salteado, hilo de lino.

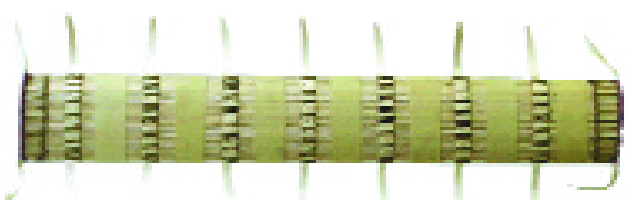

Refuerzo del lomo después de la costura.

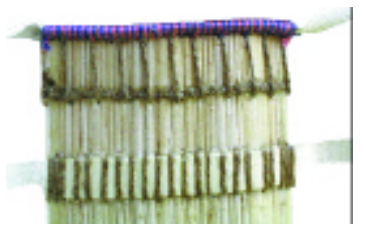

Cabezada. 


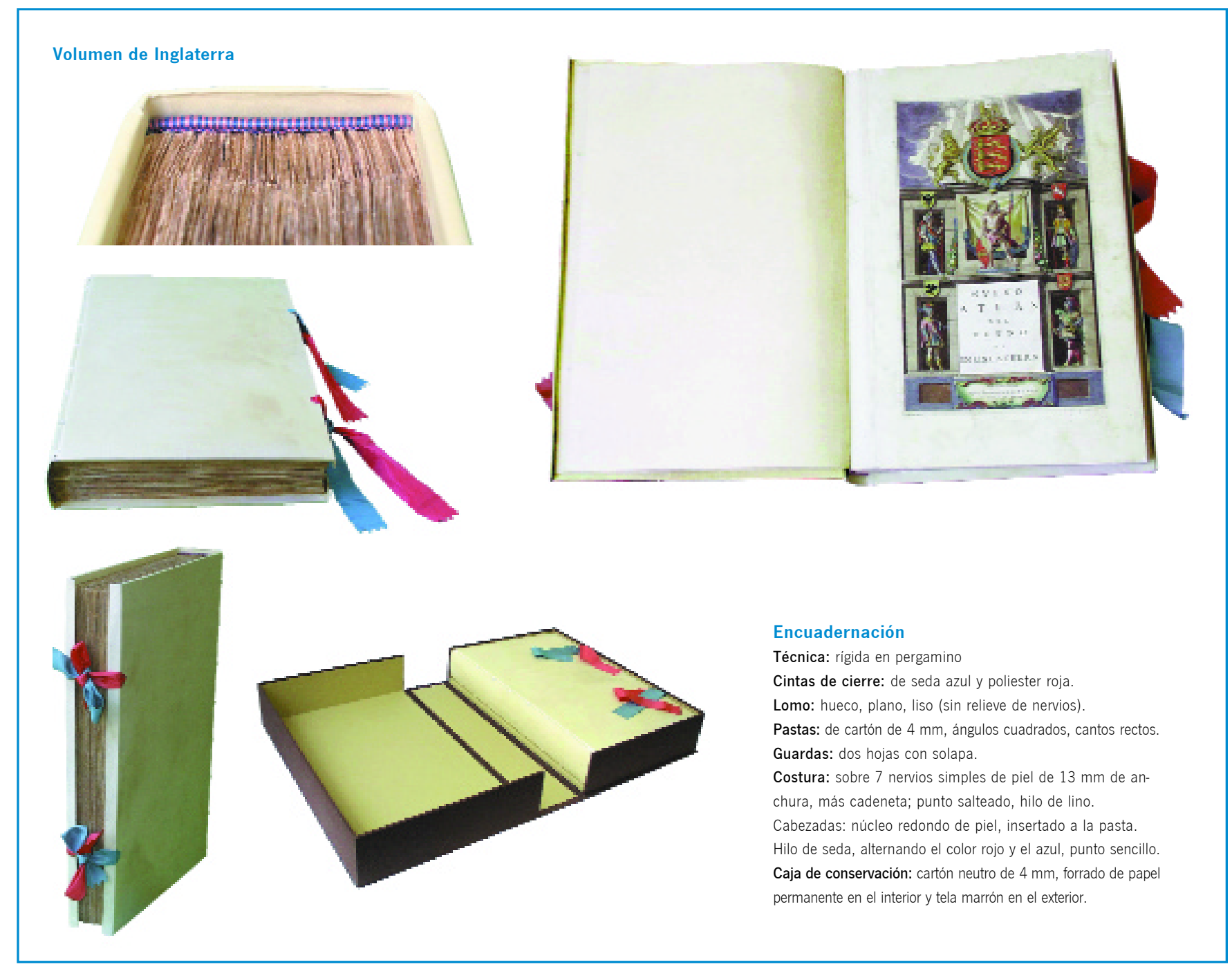

Volumen de Alemania
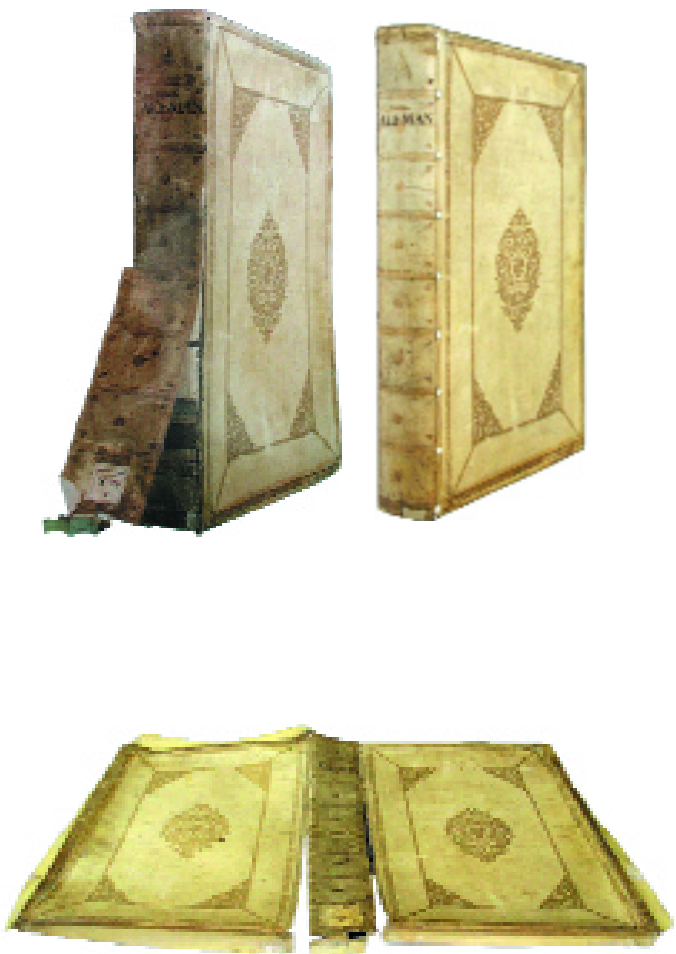

Volumen de Francia
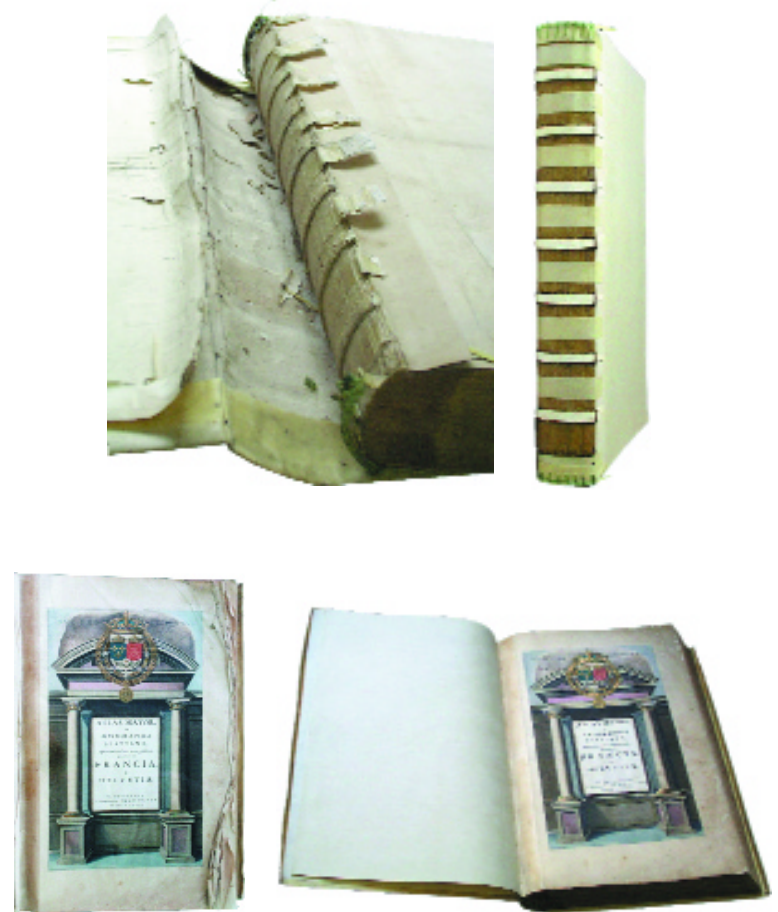


\section{$098-099$}

\section{Criterios}

Restauración del Atlas

Mayor o Geografía

Blaviana. Nuevas técnicas

de Intervención

\section{PH43 - Abril 2003}

\section{Volumen de España}
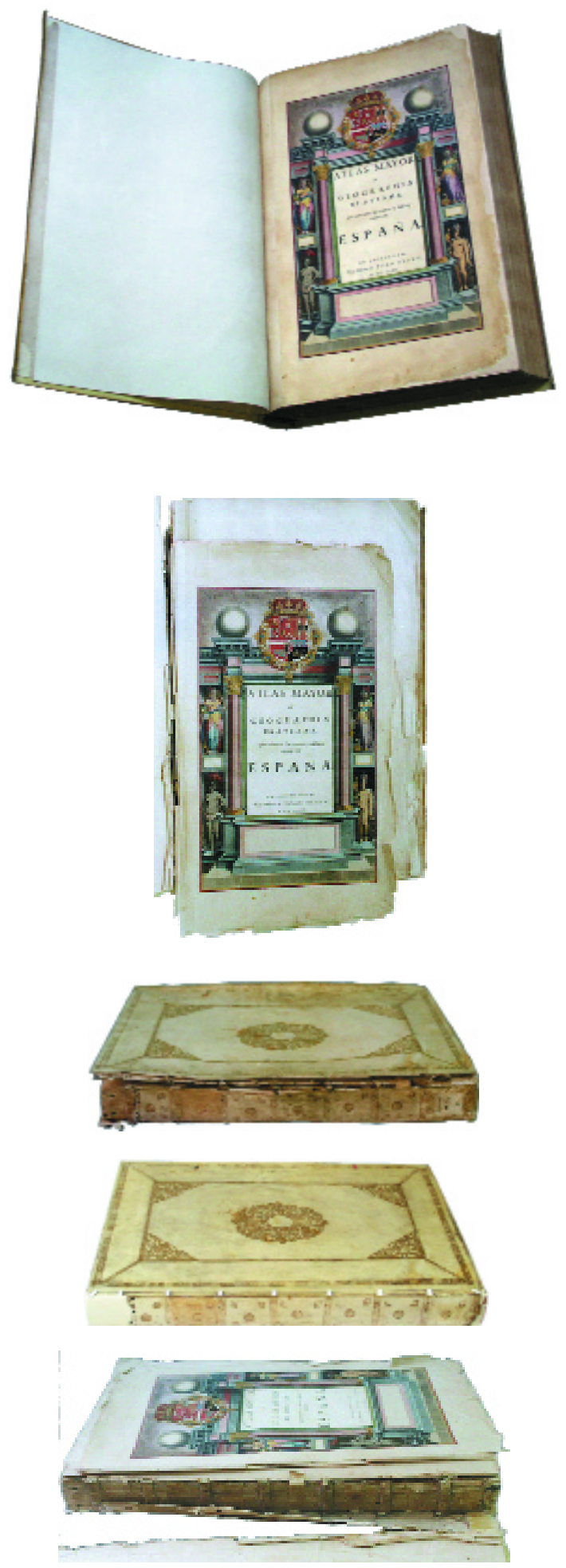

El beneficio del dosificador ha sido la precisión en la reintegración mecánica en húmedo, con él se han evitado rectificaciones y por tanto manipulaciones innecesarias de los documentos.

Paralelamente la reintegración mecánica en seco me ha permitido realizar esta operación, por primera vez, en condiciones de máxima seguridad para la integridad de documentos que como los mapas de los atlas, no es posible reintegrar mediante procedimientos acuosos.

La compensación no sólo ha sido haber logrado mejorar o resolver técnicamente los procedimientos de reintegración mecánica, sino comprobar que el resultado alcanzado es el idóneo, superando incluso las expectativas iniciales.

\section{Bibliografía}

FAUS, A. Aproximació des de la Geografia al Gran Atles i als globus celest y terraqüi de la família Blaeu, conservats a la Biblioteca de la Universitat de València. Cel i Terra. Valencia: Universitat de València, 1996, pp. 105-120

PARDO PARDO, L. Dosificador de pulpa de papel para la reintegración mecánica de soportes dañados. XI Congreso de Conservación y Restauración de Bienes Culturales. Castellón: Diputación de Castellón, 1996, pp. 329-333

\section{Equipo de trabajo}

Dirección técnica y coordinación, proceso de restauración, informe y documentación gráfica: Luciano Pardo Pardo.

Restaurador. Sección de Restauración del S.I.B. de la Universidad de Valencia

\section{Ayudantes de restauración:}

\section{Cristina Pardo Pardo y Fernando Ramón Cortina}

Análisis microbiológico: José Pedro Martínez García.

Catedrático de Microbiología

Daniel Gozalbo Flor.

Profesor Titular de Microbiología

Dpto. de Microbiología y Ecología de la Universidad de Valencia

Proyecto:

"Restauración de la Geographia Blaviana"

Responsable del proyecto profesor José Luis Canet Vallés 